\title{
Establishment of prognostic nomogram for elderly colorectal cancer patients: a SEER database analysis
}

\author{
Chaoran $\mathrm{Yu}^{1,2^{*}+}$ (1) and Yujie Zhang ${ }^{3+}$
}

\begin{abstract}
Background: This study aimed to establish nomogram models of overall survival (OS) and cancer-specific survival (CSS) in elderly colorectal cancer (ECRC) patients (Age $\geq 70$ ).

Methods: The clinical variables of patients confirmed as ECRC between 2004 and 2016 were retrieved from the Surveillance, Epidemiology, and End Results (SEER) database. Univariate and multivariate analysis were performed, followed by the construction of nomograms in OS and CSS.

Results: A total of 44,761 cases were finally included in this study. Both C-index and calibration plots indicated noticeable performance of newly established nomograms. Moreover, nomograms also showed higher outcomes of decision curve analysis (DCA) and the area under the curve (AUC) compared to American Joint Committee on Cancer (AJCC) tumor-node-metastasis (TNM) stage and SEER stage.

Conclusions: This study established nomograms of elderly colorectal cancer patients with distinct clinical values compared to AJCC TNM and SEER stages regarding both OS and CSS.
\end{abstract}

Keywords: Elderly colon cancer, Nomogram, Overall survival, Cancer-specific survival, SEER

\section{Background}

Colorectal cancer has been ranked as the second most common malignancy in women and third in men across the world. Annual global incidence is approximately 1.4 million with nearly 700,000 deaths $[1,2]$. There are more than 50,000 death reports and over 130,000 newly occurred cases in the United States [2]. In European Union, 215,000 cases have been reported with colorectal cancer being listed as the second common cause of death [3]. In China, colorectal cancer is listed as one of

\footnotetext{
* Correspondence: chaoran_yu@yeah.net; chaoran_yu@sjtu.edu.cn

${ }^{\dagger}$ Chaoran Yu and Yujie Zhang contributed equally to this work.

${ }^{1}$ Fudan University Shanghai Cancer Center, Fudan University, Dongan Road 270, Shanghai 200025, P. R. China

${ }^{2}$ Department of Oncology, Shanghai Medical College, Fudan University, Dongan Road 270, Shanghai 200025, P. R. China

Full list of author information is available at the end of the article
}

the five most commonly malignancies both in men and women [4].

Genomic characterization of colorectal cancer has been well elucidated and the role of immunology is increasingly valued [5-7]. Therapeutically, surgical intervention and chemotherapy-based strategies have been widely accepted for colorectal cancer $[8,9]$. Noteworthy, the impact of colorectal cancer surgery on the elder group, regarding long term survival, is similar to that of younger group [10].

Generally, elderly colorectal cancer patients (ECRC), defined by age surpass 70 years old, may naturally associate with increased mortality as age increased. However, no study did fully cover nor depict the quantified association of age and risks for prognosis of ECRC [11, 12]. Previously, tumor-node-metastasis (TNM) stage system of American Joint Committee on

C C The Author(s). 2020 Open Access This article is licensed under a Creative Commons Attribution 4.0 International License, which permits use, sharing, adaptation, distribution and reproduction in any medium or format, as long as you give appropriate credit to the original author(s) and the source, provide a link to the Creative Commons licence, and indicate if changes were made. The images or other third party material in this article are included in the article's Creative Commons licence, unless indicated otherwise in a credit line to the material. If material is not included in the article's Creative Commons licence and your intended use is not permitted by statutory regulation or exceeds the permitted use, you will need to obtain permission directly from the copyright holder. To view a copy of this licence, visit http://creativecommons.org/licenses/by/4.0/. The Creative Commons Public Domain Dedication waiver (http://creativecommons.org/publicdomain/zero/1.0/) applies to the data made available in this article, unless otherwise stated in a credit line to the data. 


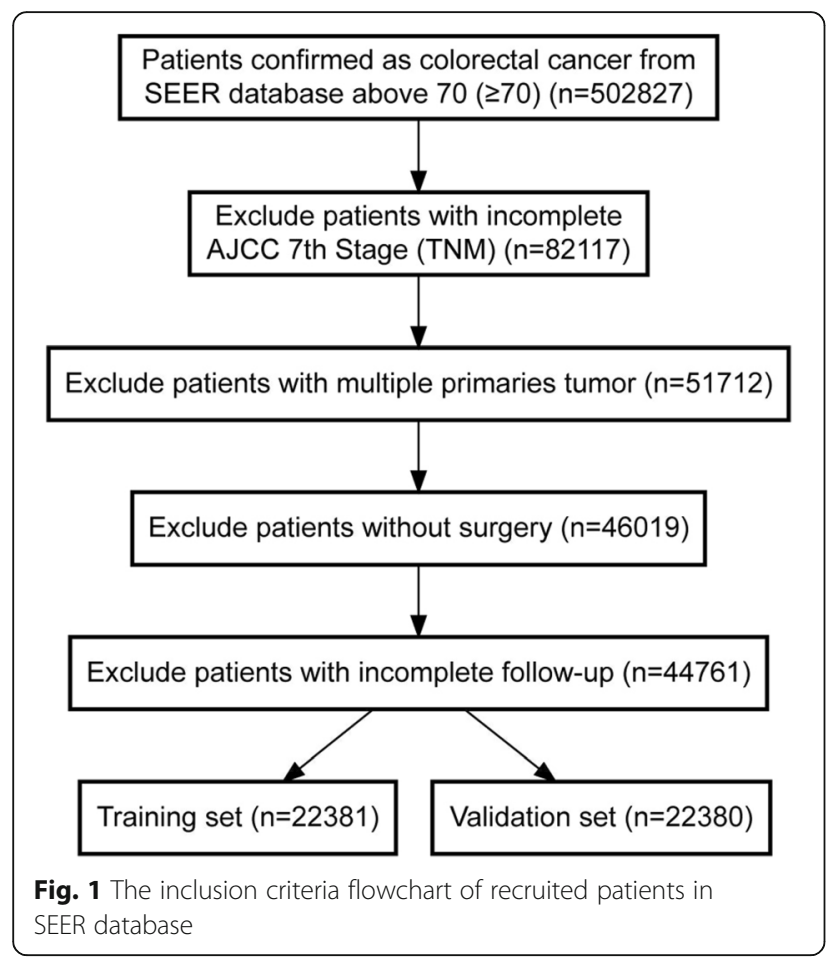

Cancer (AJCC) is widely used in the therapeutic and prognostic administration of colorectal cancer. Given increasing values of multiple variables, including tumor size and marital status, have been noticed [13, 14], a more comprehensive prognostic predictor is necessary for ECRC.

Of note, knowledge regarding the clinical prediction of ECRC is limited, with very few studies focusing on the nomogram implementation. In this study, a ECRCtargeting nomogram was established for prognostic prediction based on large sample size retrieved from the Surveillance, Epidemiology, and End Results (SEER) database in hopes of elucidating further prognostic insights [15].

\section{Methods}

Recruitment of patients from SEER database

The clinical variables of patients confirmed as ECRC between 2004 and 2016 were retrieved from the SEER database, a program established by National Cancer Institute aiming for comprehensively national-level clinical investigation [16, 17]. The reference number was 16,595-Nov2018. The inclusion criteria were: 1) colon and rectum (site recode, international classification of diseases for oncology (ICD-O-3)/WHO 2009); 2) age $\geq 70$; 3) complete information on TNM stage; 4) only one primary tumor cases were selected; 5)

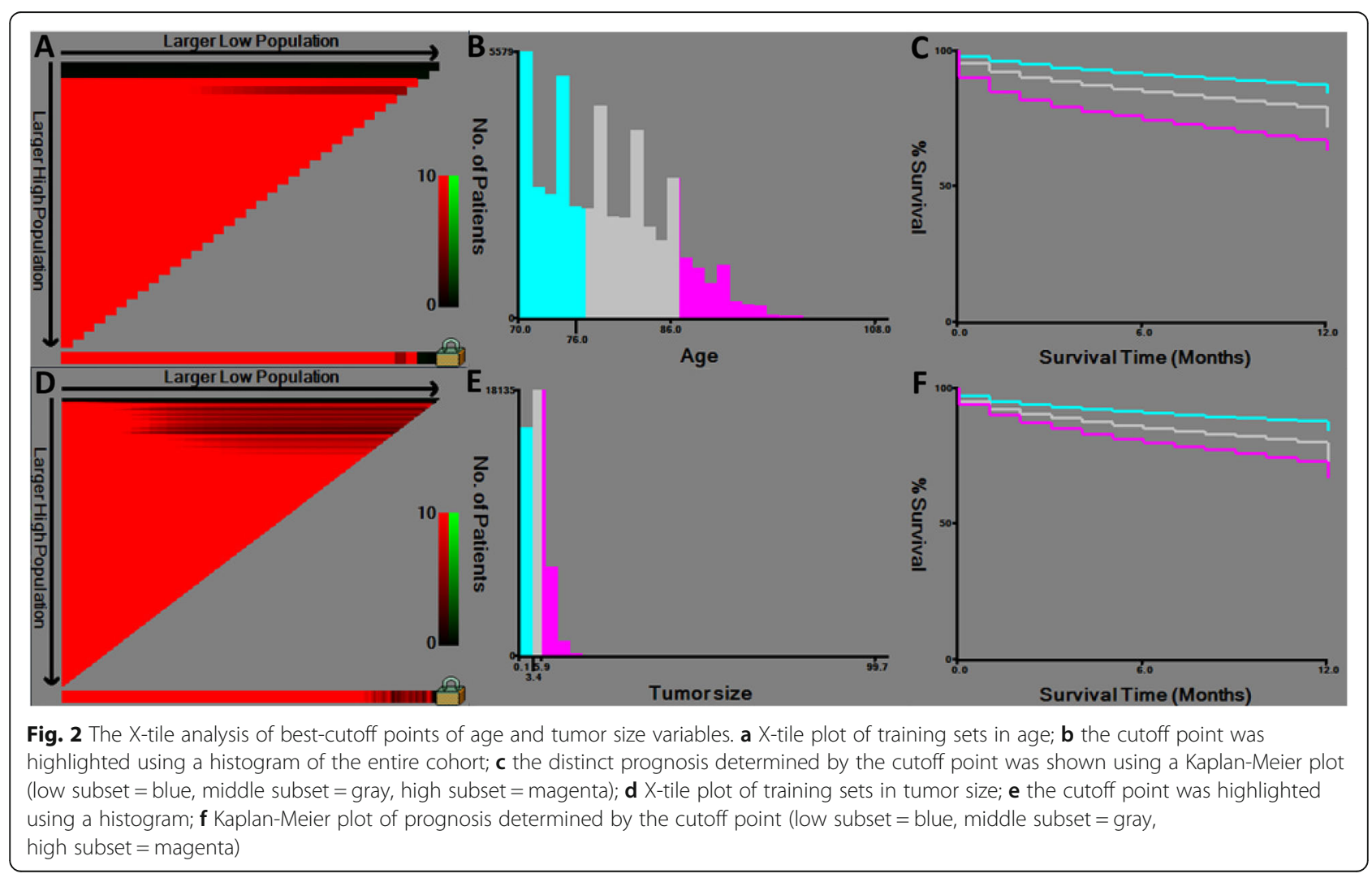


Table 1 Baseline demographic and clinical characteristics of elderly patients with CRC

\begin{tabular}{|c|c|c|c|c|}
\hline Variables & $\begin{array}{l}\text { Total } \\
(n=44,761)\end{array}$ & Training cohort $(n=22,381)$ & Validation cohort $(n=22,380)$ & $P^{\#}$ \\
\hline Sex & & & & 0.105 \\
\hline Male & $19,969(44.6)$ & $10,070(45.0)$ & 9899 (44.2) & \\
\hline Female & $24,792(55.4)$ & $12,311(55.0)$ & $12,481(55.8)$ & \\
\hline Age & & & & 0.953 \\
\hline$<=76$ & $18,287(40.9)$ & 9148 (40.9) & 9139 (40.8) & \\
\hline $77-86$ & $19,901(44.5)$ & 9937 (44.4) & 9964 (44.5) & \\
\hline$>=87$ & $6573(14.7)$ & $3296(14.7)$ & 3277 (14.6) & \\
\hline Marital status & & & & 0.310 \\
\hline Unmarried & $21,287(47.6)$ & $10,563(47.2)$ & $10,724(47.9)$ & \\
\hline Married & $20,927(46.8)$ & $10,534(47.1)$ & $10,393(46.4)$ & \\
\hline Unknown & $2547(5.7)$ & $1284(5.7)$ & $1263(5.6)$ & \\
\hline Tumor site & & & & 0.530 \\
\hline Colon & $36,652(81.9)$ & $18,352(82.0)$ & $18,300(81.8)$ & \\
\hline Rectum & 8109 (18.1) & $4029(18.0)$ & $4080(18.2)$ & \\
\hline Grade & & & & 0.346 \\
\hline । & 3870 (8.6) & 1919 (8.6) & $1951(8.7)$ & \\
\hline$\|$ & $29,426(65.7)$ & $14,665(65.5)$ & $14,761(66.0)$ & \\
\hline III & 7478 (16.7) & 3781 (16.9) & 3697 (16.5) & \\
\hline IV & $1642(3.7)$ & 806 (3.6) & $836(3.7)$ & \\
\hline Unknown & $2345(5.2)$ & $1210(5.4)$ & $1135(5.1)$ & \\
\hline SEER_stage & & & & 0.994 \\
\hline Localized & $19,923(44.5)$ & $9957(44.5)$ & $9966(44.5)$ & \\
\hline Regional & $19,512(43.6)$ & $9758(43.6)$ & 9754 (43.6) & \\
\hline Distant & $5326(11.9)$ & $2666(11.9)$ & $2660(11.9)$ & \\
\hline AJCC_stage & & & & 0.797 \\
\hline I & $12,173(27.2)$ & $6065(27.1)$ & $6108(27.3)$ & \\
\hline$\|$ & $14,656(32.7)$ & 7300 (32.6) & 7356 (32.9) & \\
\hline III & $13,071(29.2)$ & $6581(29.4)$ & $6490(29.0)$ & \\
\hline IV & $4861(10.9)$ & $2435(10.9)$ & $2426(10.8)$ & \\
\hline AJCC_T & & & & 0.674 \\
\hline $\mathrm{T} 1$ & 7352 (16.4) & $3665(16.4)$ & 3687 (16.5) & \\
\hline $\mathrm{T} 2$ & $6570(14.7)$ & $3243(14.5)$ & $3327(14.9)$ & \\
\hline T3 & $23,269(52.0)$ & $11,669(52.1)$ & $11,600(51.8)$ & \\
\hline T4 & 7570 (16.9) & $3804(17.0)$ & 3766 (16.8) & \\
\hline AJCC_N & & & & 0.271 \\
\hline NO & $27,879(62.3)$ & $13,893(62.1)$ & $13,986(62.5)$ & \\
\hline N1 & $10,677(23.9)$ & $5410(24.2)$ & $5267(23.5)$ & \\
\hline $\mathrm{N} 2$ & 6205 (13.9) & 3078 (13.8) & 3127 (14.0) & \\
\hline AJCC_M & & & & 0.893 \\
\hline MO & $39,900(89.1)$ & 19,946 (89.1) & $19,954(89.2)$ & \\
\hline M1 & 4861 (10.9) & $2435(10.9)$ & $2426(10.8)$ & \\
\hline Bone metastasis & & & & 0.990 \\
\hline No & $44,314(99.0)$ & 22,158 (99.0) & $22,156(99.0)$ & \\
\hline
\end{tabular}


Table 1 Baseline demographic and clinical characteristics of elderly patients with CRC (Continued)

\begin{tabular}{|c|c|c|c|c|}
\hline Variables & $\begin{array}{l}\text { Total } \\
(n=44,761)\end{array}$ & Training cohort $(n=22,381)$ & Validation cohort $(n=22,380)$ & $P^{\#}$ \\
\hline Yes & $119(0.3)$ & $60(0.3)$ & $59(0.3)$ & \\
\hline Unknown & $328(0.7)$ & $163(0.7)$ & $165(0.7)$ & \\
\hline Brain metastasis & & & & 0.700 \\
\hline No & 44,375 (99.1) & $22,193(99.2)$ & $22,182(99.1)$ & \\
\hline Yes & $41(0.1)$ & $22(0.1)$ & $19(0.1)$ & \\
\hline Unknown & $345(0.8)$ & $166(0.7)$ & $179(0.8)$ & \\
\hline Liver metastasis & & & & 0.978 \\
\hline No & $41,350(92.4)$ & $20,677(92.4)$ & $20,673(92.4)$ & \\
\hline Yes & $3138(7.0)$ & $1566(7.0)$ & $1572(7.0)$ & \\
\hline Unknown & $273(0.6)$ & $138(0.6)$ & $135(0.6)$ & \\
\hline Lung metastasis & & & & 0.586 \\
\hline No & $43,655(97.5)$ & 21,837 (97.6) & $21,818(97.5)$ & \\
\hline Yes & $784(1.8)$ & $379(1.7)$ & 405 (1.8) & \\
\hline Unknown & $322(0.7)$ & $165(0.7)$ & $157(0.7)$ & \\
\hline Tumor size & & & & 0.678 \\
\hline$<=3.4$ & $13,341(29.8)$ & 6625 (29.6) & $6716(30.0)$ & \\
\hline $3.5-5.9$ & $16,250(36.3)$ & $8142(36.4)$ & 8108 (36.2) & \\
\hline$>=6$ & $11,387(25.4)$ & 5736 (25.6) & $5651(25.3)$ & \\
\hline Unknown & $3783(8.5)$ & $1878(8.4)$ & 1905 (8.5) & \\
\hline
\end{tabular}

\# Chi-square test

surgery performed in each case. Next, all included cases were randomly divided into training and validation sets with equal sample size. In addition, $x$-tile software was used to determine and visualize the best cutoff points of age and tumor size variables in this study [18].

\section{Clinical variables extracted for analysis}

Age, sex, marital status, tumor site, histological grade, SEER stage, the AJCC TNM stage, distant metastasis (bone, brain, liver and lung) and tumor size were all selected for the establishment of nomogram modeling. Regarding the clinical outcome, overall survival (OS) and cancer-specific survival (CSS) were chosen as the primary and second endpoints.

\section{Construction and validation of the nomogram}

Statistically, chi-square test was used for all included categories between training and validation groups. Next, univariate and multivariate analysis were used to determine distinct variables, which were further output for the construction of nomogram model by $\mathrm{R}$ software 3.3.0 ( $\mathrm{R}$ Foundation for Statistical Computing, Vienna, Austria, www.r-project.org). Then, the validation group was used for the assessment of the newly established nomogram. The comparison between the nomogram prediction and observed outcomes was assessed by the concordance index (C-index). The calibration plot was used for visualized comparison between prognosis predicted by nomogram and actual ones. Sensitivity and specificity were evaluated by receiver operating characteristics curve (ROC)-the area under the curve (AUC). Furthermore, the power of nomogram model was also compared to the TNM stage and SEER stage in both ROC and decision curve analysis (DCA). All analysis was achieved by $\mathrm{R}$ software 3.3.0, with $p$ value $<0.05$ considered as statistically significant.

\section{Results}

\section{Characterization of included cases}

Following inclusion criteria, a total of 44,761 cases were finally included in this study with 22,381 assigned to training set and 22,380 to validation set randomly (Fig. 1). Among all patients, $44.6 \%$ were male and $55.4 \%$ female; $47.6 \%$ were unmarried and $46.8 \%$ married; $81.9 \%$ were colon cancer and $18.1 \%$ rectal cancer; $0.3 \%$ of cases had bone metastasis, $0.1 \%$ with brain metastasis, $7.0 \%$ with liver metastasis, $1.8 \%$ with lung metastasis. The cutoff points of age and tumor size were determined by $x$-tile (Fig. 2). Specifically, $40.9 \%$ were $<=76$ years old, $44.5 \%$ between 77 and 86 years old, and $14.7 \%>=87$ years old. $29.8 \%$ 
Table 2 Univariate and multivariate analysis of overall survival in the training cohort

\begin{tabular}{|c|c|c|c|}
\hline \multirow[t]{2}{*}{ Variables } & \multirow{2}{*}{$\begin{array}{l}\text { Univariate analysis } \\
P\end{array}$} & \multicolumn{2}{|c|}{ Multivariate analysis } \\
\hline & & HR (95\% Cl) & $P$ \\
\hline Sex & 0.060 & & \\
\hline Male & & Reference & \\
\hline Female & & $0.786(0.752-0.822)$ & $<0.001$ \\
\hline Age & $<0.001$ & & \\
\hline$<=76$ & & Reference & \\
\hline $77-86$ & & $1.725(1.643-1.811)$ & $<0.001$ \\
\hline$>=87$ & & $2.868(2.699-3.047)$ & $<0.001$ \\
\hline Marital status & $<0.001$ & & \\
\hline Unmarried & & Reference & \\
\hline Married & & $0.762(0.727-0.798)$ & $<0.001$ \\
\hline Unknown & & $0.957(0.873-1.050)$ & 0.351 \\
\hline Tumor site & $<0.001$ & & \\
\hline Colon & & Reference & \\
\hline Rectum & & $0.991(0.936-1.050)$ & 0.765 \\
\hline Grade & $<0.001$ & & \\
\hline I & & Reference & \\
\hline$\|$ & & $1.114(1.022-1.215)$ & 0.014 \\
\hline III & & $1.315(1.195-1.447)$ & $<0.001$ \\
\hline IV & & $1.413(1.247-1.601)$ & $<0.001$ \\
\hline Unknown & & $1.146(1.005-1.307)$ & 0.042 \\
\hline SEER_stage & $<0.001$ & & \\
\hline Localized & & Reference & \\
\hline Regional & & $1.047(0.973-1.126)$ & 0.222 \\
\hline Distant & & $1.181(0.975-1.431)$ & 0.088 \\
\hline AJCC_stage & $<0.001$ & & \\
\hline I & & - & - \\
\hline$\|$ & & - & - \\
\hline III & & - & - \\
\hline IV & & - & - \\
\hline AJCC_T & $<0.001$ & & \\
\hline $\mathrm{T} 1$ & & Reference & \\
\hline $\mathrm{T} 2$ & & 1.083(0.979-1.199) & 0.123 \\
\hline T3 & & $1.353(1.233-1.486)$ & $<0.001$ \\
\hline $\mathrm{T} 4$ & & $2.173(1.953-2.418)$ & $<0.001$ \\
\hline AJCC_N & $<0.001$ & & \\
\hline NO & & Reference & \\
\hline N1 & & $1.365(1.282-1.453)$ & $<0.001$ \\
\hline N2 & & $1.975(1.845-2.113)$ & $<0.001$ \\
\hline AJCC_M & $<0.001$ & & \\
\hline MO & & Reference & \\
\hline M1 & & $2.017(1.662-2.448)$ & $<0.001$ \\
\hline Bone metastasis & $<0.001$ & & \\
\hline No & & Reference & \\
\hline
\end{tabular}


Table 2 Univariate and multivariate analysis of overall survival in the training cohort (Continued)

\begin{tabular}{|c|c|c|c|}
\hline \multirow[t]{2}{*}{ Variables } & \multirow{2}{*}{$\begin{array}{l}\text { Univariate analysis } \\
P\end{array}$} & \multicolumn{2}{|c|}{ Multivariate analysis } \\
\hline & & HR (95\% CI) & $P$ \\
\hline Yes & & $1.393(1.058-1.835)$ & 0.018 \\
\hline Unknown & & $1.507(0.909-2.500)$ & 0.112 \\
\hline Brain metastasis & $<0.001$ & & \\
\hline No & & Reference & \\
\hline Yes & & $2.145(1.401-3.285)$ & $<0.001$ \\
\hline Unknown & & $0.687(0.415-1.135)$ & 0.142 \\
\hline Liver metastasis & $<0.001$ & & \\
\hline No & & Reference & \\
\hline Yes & & $1.329(1.209-1.462)$ & $<0.001$ \\
\hline Unknown & & $0.962(0.684-1.352)$ & 0.822 \\
\hline Lung metastasis & $<0.001$ & & \\
\hline No & & Reference & \\
\hline Yes & & $1.327(1.178-1.495)$ & $<0.001$ \\
\hline Unknown & & $1.432(1.033-1.984)$ & 0.031 \\
\hline Tumor size & $<0.001$ & & \\
\hline$<=3.4$ & & Reference & \\
\hline $3.5-5.9$ & & $1.026(0.968-1.088)$ & 0.379 \\
\hline$>=6$ & & $1.137(1.069-1.210)$ & $<0.001$ \\
\hline Unknown & & $1.272(1.156-1.398)$ & $<0.001$ \\
\hline
\end{tabular}

were $<=3.4 \mathrm{~cm}, \quad 36.3 \%$ between $3.5-5.9 \mathrm{~cm}$ and $25.4 \%>=6 \mathrm{~cm}$ (Table 1). No significant difference was identified between training and validation cohorts regarding each included variable.

\section{Establishment of the nomogram}

Interestingly, sex, age, marital status, tumor size, grade, SEER stage, AJCC TNM stage, bone metastasis, brain metastasis, liver metastasis, lung metastasis and tumor size were all displayed high statistically difference in univariate OS analysis (Table 2). Next, sex, age, marital status, grade, AJCC TNM, bone metastasis, brain metastasis, liver metastasis and lung metastasis and tumor size were all significantly identified in OS multivariate analysis (Table 2). Meanwhile in CSS, age, marital status, tumor site, grade, SEER stage, AJCC TNM stage, bone metastasis, brain metastasis, liver metastasis, lung metastasis and tumor size were significantly identified in univariate CSS analysis. Age, marital status, tumor site, grade, SEER stage, AJCC TNM, bone metastasis, brain metastasis, liver metastasis, lung metastasis and tumor size were significantly associated with CSS in multivariate analysis (Table 3). Thus, OS and CSS nomogram models of 1-, 3- and 5-year were established, respectively (Fig. 3a, b).

\section{Nomogram validation}

The assessment was performed both internally and externally, measured by C-index and calibration plots. Specifically, C-index of OS nomogram was 0.726 (95\% confidence interval (95\%CI): 0.720-0.732) in training set while 0.722 (95\%CI: $0.716-0.728)$ in validation set (Table 4. C-index of CSS was 0.791 (95\%CI: 0.7850.797 ) in training set while 0.789 (95\%CI: 0.783-0.795) (Table 4). Meanwhile, calibration plots indicated high quality of predicted outcome of OS/CSS nomogram models (Figs. 4, 5). Next, to further compare the nomograms with other classic staging methods, including AJCC TNM stage and SEER stage, DCA and ROC were performed in both OS and CSS. In DCA, nomograms both in OS and CSS showed superior power to AJCC TNM stage and SEER stage (Fig. 6). Meanwhile, nomograms in OS and CSS also showed higher statistic power to AJCC TNM stage and SEER stage (Figs. 7, 8, Table 5).

\section{Discussion}

Up to now, numerous studies had investigated the role of prognostic nomograms for colorectal cancer patients using SEER database for variable objects $[19,20]$. In fact, increasing studies tended to focus more on the therapeutics or modified classification, with very rare 
Table 3 Univariate and multivariate analysis of cancer-specific survival in the training cohort

\begin{tabular}{|c|c|c|c|}
\hline \multirow[t]{2}{*}{ Variables } & \multirow{2}{*}{$\begin{array}{l}\text { Univariate analysis } \\
P\end{array}$} & \multirow{2}{*}{$\begin{array}{l}\text { Multivariate analysis } \\
\text { HR }(95 \% \mathrm{Cl})\end{array}$} & \multirow[t]{2}{*}{$P$} \\
\hline & & & \\
\hline Sex & 0.644 & & \\
\hline Male & & - & - \\
\hline Female & & - & - \\
\hline Age & $<0.001$ & & \\
\hline$<=76$ & & Reference & \\
\hline $77-86$ & & $1.499(1.412-1.592)$ & $<0.001$ \\
\hline$>=87$ & & $2.252(2.083-2.435)$ & $<0.001$ \\
\hline Marital status & $<0.001$ & & \\
\hline Unmarried & & Reference & \\
\hline Married & & $0.836(0.791-0.884)$ & $<0.001$ \\
\hline Unknown & & $1.011(0.896-1.140)$ & 0.865 \\
\hline Tumor site & $<0.001$ & & \\
\hline Colon & & Reference & \\
\hline Rectum & & $1.088(1.011-1.171)$ & 0.024 \\
\hline Grade & $<0.001$ & & \\
\hline I & & Reference & \\
\hline$\|$ & & $1.061(0.943-1.194)$ & 0.326 \\
\hline III & & $1.324(1.168-1.502)$ & $<0.001$ \\
\hline IV & & $1.417(1.212-1.657)$ & $<0.001$ \\
\hline Unknown & & $1.100(0.916-1.321)$ & 0.308 \\
\hline SEER_stage & $<0.001$ & & \\
\hline Localized & & Reference & \\
\hline Regional & & $1.492(1.343-1.657)$ & $<0.001$ \\
\hline Distant & & $1.883(1.507-2.354)$ & $<0.001$ \\
\hline AJCC_stage & $<0.001$ & & \\
\hline I & & - & - \\
\hline$\|$ & & - & - \\
\hline III & & - & - \\
\hline IV & & - & - \\
\hline AJCC_T & $<0.001$ & & \\
\hline $\mathrm{T} 1$ & & Reference & \\
\hline $\mathrm{T} 2$ & & $1.417(1.185-1.694)$ & $<0.001$ \\
\hline T3 & & $2.244(1.912-2.634)$ & $<0.001$ \\
\hline $\mathrm{T} 4$ & & $3.914(3.301-4.640)$ & $<0.001$ \\
\hline AJCC_N & $<0.001$ & & \\
\hline NO & & Reference & \\
\hline N1 & & $1.561(1.444-1.687)$ & $<0.001$ \\
\hline N2 & & $2.426(2.237-2.631)$ & $<0.001$ \\
\hline AJCC_M & $<0.001$ & & \\
\hline MO & & Reference & \\
\hline M1 & & $2.160(1.743-2.677)$ & $<0.001$ \\
\hline Bone metastasis & $<0.001$ & & \\
\hline No & & Reference & \\
\hline
\end{tabular}


Table 3 Univariate and multivariate analysis of cancer-specific survival in the training cohort (Continued)

\begin{tabular}{|c|c|c|c|}
\hline \multirow[t]{2}{*}{ Variables } & \multirow{2}{*}{$\begin{array}{l}\text { Univariate analysis } \\
P\end{array}$} & \multirow{2}{*}{$\begin{array}{l}\text { Multivariate analysis } \\
\text { HR }(95 \% \mathrm{Cl})\end{array}$} & \multirow[t]{2}{*}{$P$} \\
\hline & & & \\
\hline Yes & & $1.360(1.021-1.812)$ & 0.036 \\
\hline Unknown & & $1.600(0.934-2.743)$ & 0.087 \\
\hline Brain metastasis & $<0.001$ & & \\
\hline No & & Reference & \\
\hline Yes & & $2.424(1.564-3.756)$ & $<0.001$ \\
\hline Unknown & & $0.602(0.346-1.049)$ & 0.073 \\
\hline Liver metastasis & $<0.001$ & & \\
\hline No & & Reference & \\
\hline Yes & & $1.414(1.280-1.563)$ & $<0.001$ \\
\hline Unknown & & $1.047(0.724-1.514)$ & 0.807 \\
\hline Lung metastasis & $<0.001$ & & \\
\hline No & & Reference & \\
\hline Yes & & $1.359(1.200-1.539)$ & $<0.001$ \\
\hline Unknown & & $1.439(1.020-2.029)$ & 0.038 \\
\hline Tumor size & $<0.001$ & & \\
\hline$<=3.4$ & & Reference & \\
\hline $3.5-5.9$ & & $1.017(0.942-1.097)$ & 0.670 \\
\hline$>=6$ & & $1.186(1.095-1.283)$ & $<0.001$ \\
\hline Unknown & & 1.394(1.221-1.592) & $<0.001$ \\
\hline
\end{tabular}
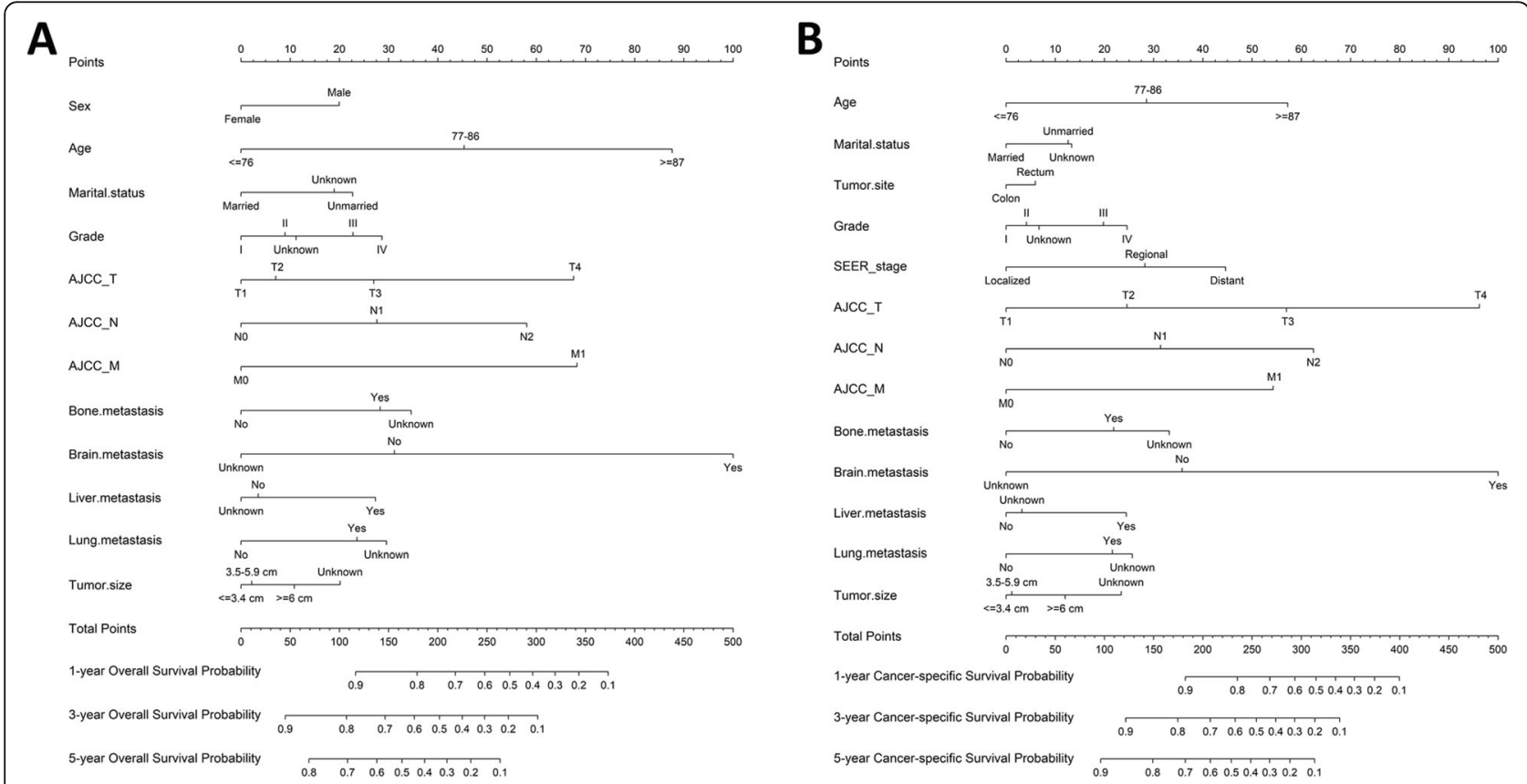

Fig. 3 Establishment of overall survival (OS) and cancer-specific survival (CSS) nomograms. a Construction of OS nomogram; b construction of CSS nomogram 
Table 4 C-indexes for the nomograms and other stage systems in patients with CRC

\begin{tabular}{|c|c|c|c|c|c|c|c|}
\hline \multirow[t]{2}{*}{ Survival } & & \multicolumn{3}{|c|}{ Training set } & \multicolumn{3}{|c|}{ Validation set } \\
\hline & & $\overline{\mathrm{HR}}$ & $95 \% \mathrm{Cl}$ & $P$ & HR & $95 \% \mathrm{Cl}$ & $P$ \\
\hline \multirow[t]{3}{*}{ OS } & Nomogram & 0.726 & $0.720-0.732$ & Reference & 0.722 & $0.716-0.728$ & Reference \\
\hline & SEER stage & 0.649 & $0.643-0.655$ & $<0.001$ & 0.65 & $0.644-0.656$ & $<0.001$ \\
\hline & 7th edition TNM stage & 0.682 & $0.676-0.688$ & $<0.001$ & 0.681 & $0.675-0.687$ & $<0.001$ \\
\hline \multirow[t]{3}{*}{ CSS } & Nomogram & 0.791 & $0.785-0.797$ & Reference & 0.789 & $0.783-0.795$ & Reference \\
\hline & SEER stage & 0.728 & $0.721-0.735$ & $<0.001$ & 0.727 & $0.720-0.734$ & $<0.001$ \\
\hline & 7th edition TNM stage & 0.77 & $0.763-0.777$ & $<0.001$ & 0.767 & $0.760-0.774$ & $<0.001$ \\
\hline
\end{tabular}

highlighted the role of age in the prognostic assessment of colorectal cancer. Our previous study reported that a nomogram for early-onset colorectal cancer patients could display comparably higher Cindex value and better performance than conventional variables [21]. ECRC, on the other hand, had been explored with limited studies. $\mathrm{Li}$ et al. reported that, with 18,937 included cases, adjuvant chemotherapy did not offer additional survival benefits to elderly patients with stage II or III [22]. Nonetheless, a general prognostic nomogram of ECRC is yet to be fully characterized. In this study, the nomograms displayed higher C-index and convinced calibration plots for OS and CSS prediction using SEER database. Moreover, they achieved higher values regarding both AUC and DCA assessment systems compared to AJCC TNM and SEER stages.

Of note, in OS, 12 variables (sex, age, marital status, grade, AJCC TNM, bone metastasis, brain metastasis, liver metastasis and lung metastasis and tumor size) out of 15 variables were determined for the construction of nomogram. Similar feature had also been noticed in CSS nomogram. It was highly possible that the prognosis of ECRC could be associated with more variables than common colorectal cancer cases. Moreover, four types of distant metastasis, for the first time, had been incorporated for nomogram of ECRC in SEER analysis.

In addition, X-tile tool was introduced for the best cutoff values of age and tumor size in this study. X-tile

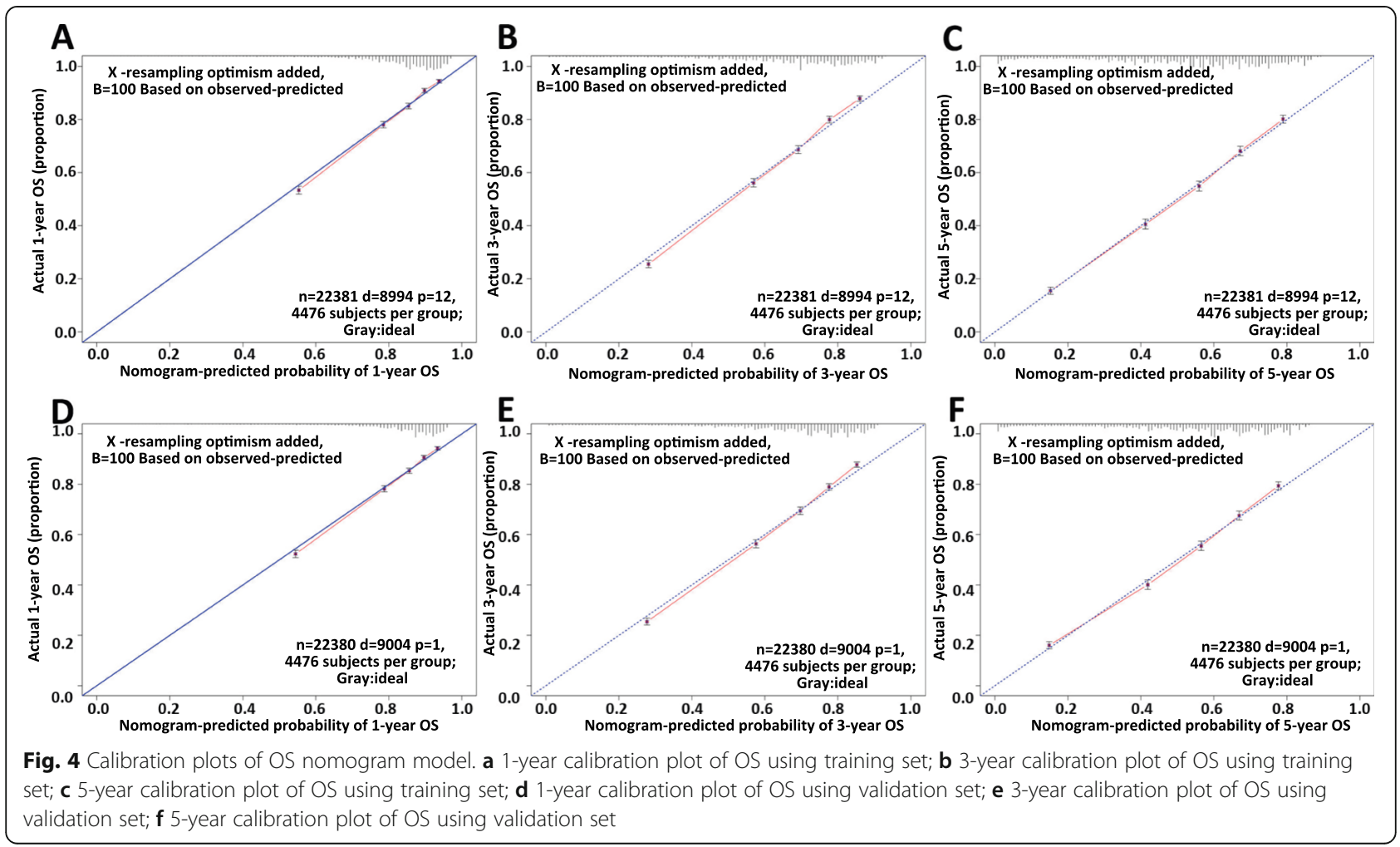



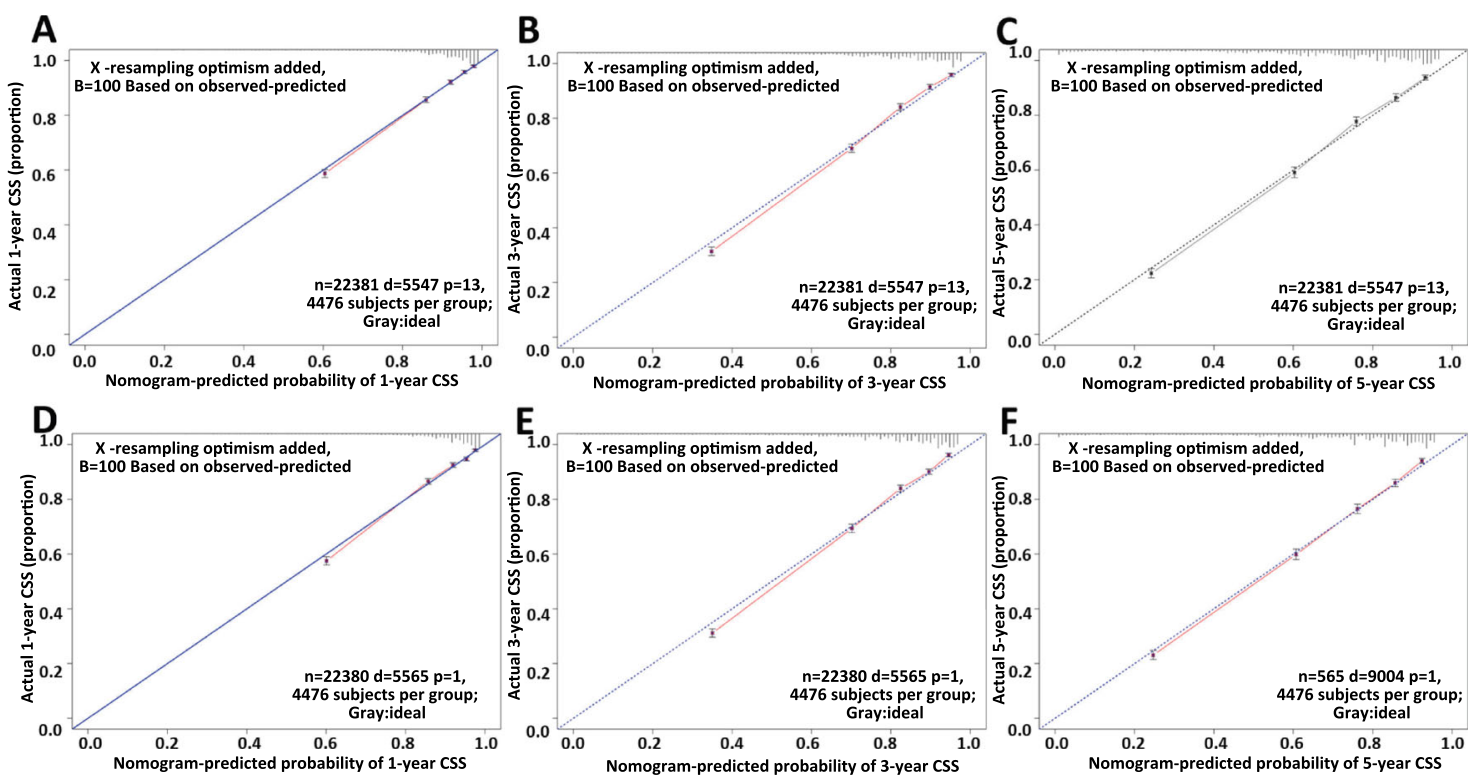

Fig. 5 Calibration plots of CSS nomogram model. a 1-year calibration plot of CSS using training set; b 3-year calibration plot of CSS using training set; c 5-year calibration plot of CSS using training set; d 1-year calibration plot of CSS using validation set; e 3-year calibration plot of CSS using validation set; $\mathbf{f}$-year calibration plot of CSS using validation set
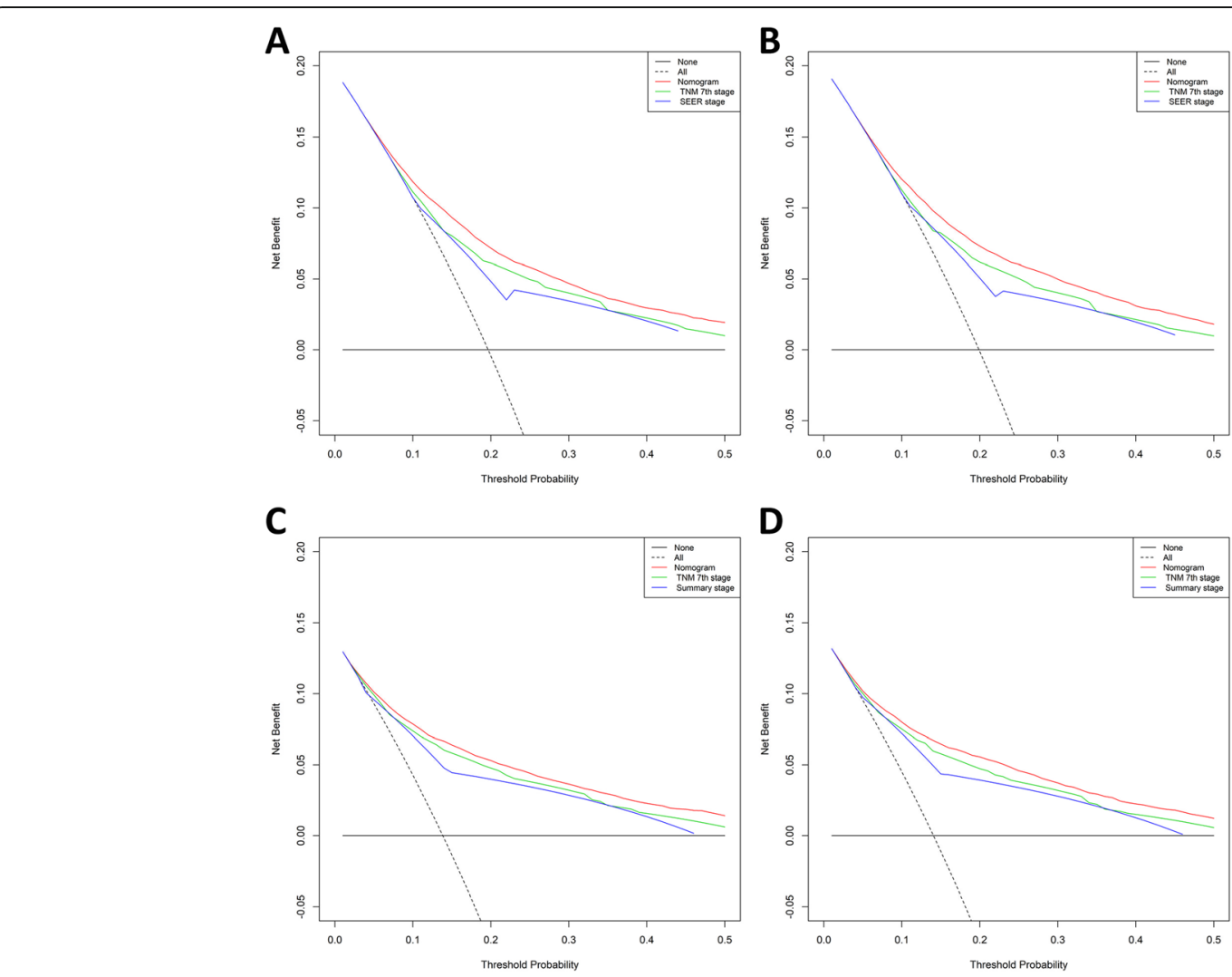

Fig. 6 Decision curve analysis (DCA) of OS and CSS nomograms. a DCA of OS nomogram using training set; b DCA of OS nomogram using validation set; $\mathbf{c}$ DCA of CSS nomogram using training set; $\mathbf{d}$ DCA of CSS nomogram using validation set 

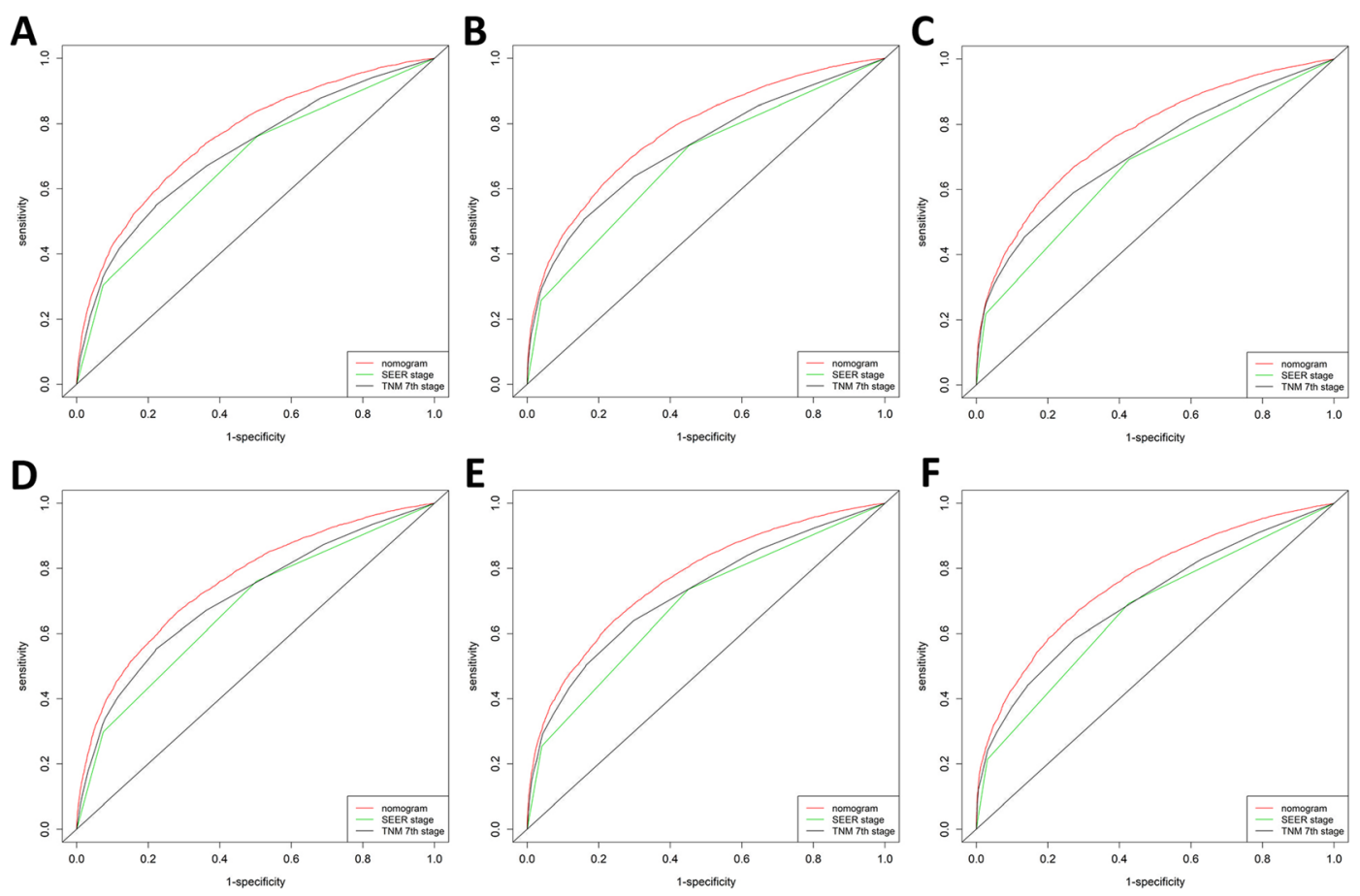

Fig. 7 Receiver operating characteristics curve (ROC) comparison of OS nomogram, AJCC TNM stage and SEER stage. a1-year ROC of OS nomogram using train set; b 3-year ROC of OS nomogram using training set; c 5-year ROC of OS nomogram using training set; $\mathbf{d} 1$-year ROC of OS nomogram using validation set; e 3-year ROC of OS nomogram using validation set; $\mathbf{f} 5$-year ROC of OS nomogram using validation set
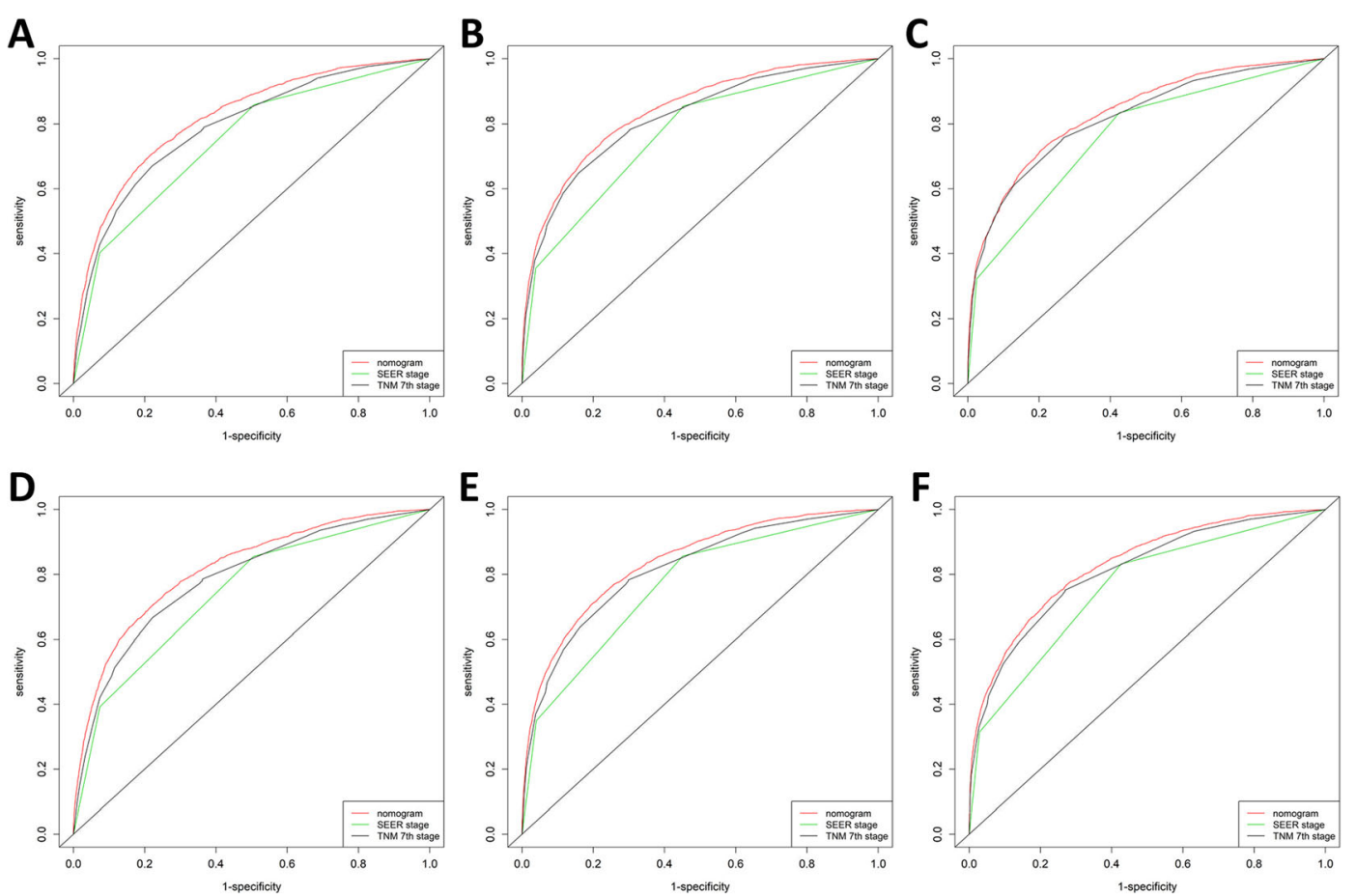

Fig. 8 ROC comparison of CSS nomogram, AJCC TNM stage and SEER stage. a 1-year ROC of CSS nomogram using train set; $\mathbf{b}$ 3-year ROC of CSS nomogram using training set; $\mathbf{c} 5$-year ROC of CSS nomogram using training set; $\mathbf{d}$ 1-year ROC of CSS nomogram using validation set; $\mathbf{e} 3$-year ROC of CSS nomogram using validation set; $\mathbf{f} 5$-year ROC of CSS nomogram using validation set 
Table 5 The area under the curve (AUC) of comparison between nomograms and AJCC TNM stage and the Surveillance, Epidemiology, and End Results (SEER) database stage

\begin{tabular}{|c|c|c|c|c|c|c|c|}
\hline \multicolumn{2}{|c|}{ Survival } & \multicolumn{6}{|l|}{ AUC } \\
\hline & & \multicolumn{3}{|c|}{ Training set } & \multicolumn{3}{|c|}{ Validation set } \\
\hline & & 1-year & 3-year & 5-year & 1-year & 3-year & 5-year \\
\hline \multirow[t]{3}{*}{$\overline{\mathrm{OS}}$} & Nomogram & 0.760 & 0.774 & 0.766 & 0.758 & 0.768 & 0.760 \\
\hline & SEER stage & 0.677 & 0.685 & 0.670 & 0.676 & 0.685 & 0.668 \\
\hline & 7th edition TNM stage & 0.714 & 0.725 & 0.712 & 0.710 & 0.723 & 0.702 \\
\hline \multirow[t]{3}{*}{ CSS } & Nomogram & 0.819 & 0.839 & 0.833 & 0.817 & 0.837 & 0.830 \\
\hline & SEER stage & 0.746 & 0.764 & 0.763 & 0.742 & 0.764 & 0.758 \\
\hline & 7th edition TNM stage & 0.790 & 0.817 & 0.817 & 0.785 & 0.814 & 0.810 \\
\hline
\end{tabular}

tool was established as a powerful graphic method to illustrate potential subsets (cutoff) with construction of a two dimensional projection [18]. It had been widely used in numerous investigations, including esophageal squamous cell carcinoma, bladder cancer and chondrosarcoma [23-25]. In this study, for the first time, subsets of consecutive variables, age and tumor size, were determined by X-tile tool. In fact, the role of tumor size had been intensively studied [26]. However, the cutoff points of tumor size in colorectal cancer remain largely arbitrary. Therefore, introduction of X-tile for the classification of tumor size could be both reliable and replicated.

Generally, elderly patients may naturally associate with increased mortality as age increased. However, no study did fully cover nor depict the quantified association of age and risks for prognosis, particularly when elderly patients had surpassed 70 years old. In our study, age itself was identified as a higher risk factor in OS compared to CSS nomogram, with age $\geq$ 87 representing nearly 90 points in OS but less than 60 points in CSS. Interestingly, female was identified as a protective factor in OS nomogram, instead of CSS nomogram. Moreover, marriage is also identified as a protective factor in both OS and CSS nomogram. By comparing OS and CSS nomograms, insightful clues had been noticed for further external clinical investigation.

\section{Conclusion}

This study established nomograms of elderly colorectal cancer patients with distinct clinical values compared to AJCC TNM and SEER stages regarding both OS and CSS.

\section{Abbreviations}

HR: Hazard ratio; 95\%Cl: 95\% confidence intervals; OS: Overall survival; CSS: Cancer-specific survival; ECRC: Elderly colorectal cancer;

SEER: Surveillance, Epidemiology, and End Results database; TNM: TumorNode-Metastasis stage; AJCC: American Joint Committee on Cancer; Cindex: Concordance index; ROC: Receiver operating characteristics curve;
DCA: Decision curve analysis; AUC: Area under receiver operating characteristics curve

Acknowledgements

Not applicable.

Authors' contributions

$Z Y$ and $C Y$ carried out data analysis. ZY and CY drafted the manuscript; ZY and $C Y$ participated in study design and data collection. All authors read and approved the final manuscript.

Funding

Not applicable.

Availability of data and materials

The data that support the findings of this study are available from SEER database but restrictions apply to the availability of these data, which were used under license for the current study (ID: 16595-Nov2018), and so are not publicly available. Data are however available from the authors upon reasonable request and with permission of SEER database.

Ethics approval and consent to participate

Not applicable. This article does not contain any studies with human participants or animals performed by any of the authors.

Consent for publication

Not applicable.

\section{Competing interests}

All authors declare no conflict of interest in this study.

\section{Author details}

${ }^{1}$ Fudan University Shanghai Cancer Center, Fudan University, Dongan Road 270, Shanghai 200025, P. R. China. ${ }^{2}$ Department of Oncology, Shanghai Medical College, Fudan University, Dongan Road 270, Shanghai 200025, P. R. China. ${ }^{3}$ Department of Gastrointestinal Surgery, Tongji Hospital, Tongji Medical College in Huazhong University of Science and Technology, Wuhan, Hubei, China.

Received: 30 June 2020 Accepted: 22 September 2020

Published online: 20 October 2020

\section{References}

1. Arnold M, Sierra MS, Laversanne M, et al. Global patterns and trends in colorectal cancer incidence and mortality [J]. Gut. 2017:66(4):683-91.

2. Siegel RL, Miller KD, Fedewa SA, et al. Colorectal cancer statistics, 2017. CA Cancer J Clin. 2017;67(3):177-93.

3. Ferlay J, Steliarova-Foucher E, Lortet-Tieulent J, Rosso S, Coebergh JW, Comber H, Forman D, Bray F. Cancer incidence and mortality patterns in Europe: estimates for 40 countries in 2012. Eur J Cancer. 2013:49(6):1374403.

4. Chen W, Zheng R, Baade PD, et al. Cancer statistics in China, 2015. CA Cancer J Clin. 2016;66(2):115-32. 
5. Network CGA. Comprehensive molecular characterization of human colon and rectal cancer. Nature. 2012;487(7407):330.

6. De Roock W, De Vriendt V, Normanno N, et al. KRAS, BRAF, PIK3CA, and PTEN mutations: implications for targeted therapies in metastatic colorectal cancer [J]. Lancet Oncol. 2011;12(6):594-603.

7. Lazarus J, Oneka MD, Barua S, et al. Mathematical modeling of the metastatic colorectal cancer microenvironment defines the importance of cytotoxic lymphocyte infiltration and presence of PD-L1 on antigen presenting cells [J]. Ann Surg Oncol. 2019;26(9):2821-30.

8. Edge SB, Compton CC. The American joint committee on Cancer: the 7th edition of the AJCC cancer staging manual and the future of TNM. Ann Surg Oncol. 2010;17(6):1471-4.

9. Benson AB, Venook AP, Cederquist L, Chan E, Chen YJ, Cooper HS, Deming D, Engstrom PF, Enzinger PC, Fichera A, Grem JL. Colon cancer, version 1. 2017, NCCN clinical practice guidelines in oncology. J Natl Compr Cancer Netw. 2017;15(3):370-98.

10. Devon KM, Vergara-Fernandez O, Victor JC, et al. Colorectal cancer surgery in elderly patients: presentation, treatment, and outcomes []]. Dis Colon Rectum. 2009:52(7):1272-7.

11. Kennedy AS, Ball DS, Cohen SJ, et al. Safety and efficacy of radioembolization in elderly ( $\geq 70$ years) and younger patients with unresectable liver-dominant colorectal cancer [J]. Clin Colorectal Cancer. 2016;15(2):141-151. e6.

12. Feliu J, Salud A, Escudero P, et al. XELOX (capecitabine plus oxaliplatin) as first-line treatment for elderly patients over 70 years of age with advanced colorectal cancer [J]. Br J Cancer. 2006;94(7):969-75.

13. Suzuki C, Blomqvist L, Sundin A, et al. The initial change in tumor size predicts response and survival in patients with metastatic colorectal cancer treated with combination chemotherapy [J]. Ann Oncol. 2012;23(4):948-54.

14. Li Q, Gan L, Liang L, et al. The influence of marital status on stage at diagnosis and survival of patients with colorectal cancer []]. Oncotarget. 2015;6(9):7339.

15. Hayat MJ, Howlader N, Reichman ME, et al. Cancer statistics, trends, and multiple primary cancer analyses from the Surveillance, Epidemiology, and End Results (SEER) Program [J]. Oncologist. 2007;12(1).

16. Hankey BF, Ries LA, Edwards BK. The surveillance, epidemiology, and end results program: a national resource. Cancer Epidemiol Prev Biomarkers. 1999;8(12):1117-21.

17. Hayat MJ, Howlader N, Reichman ME, Edwards BK. Cancer statistics, trends, and multiple primary cancer analyses from the surveillance, epidemiology, and end results (SEER) program. Oncologist. 2007;12(1):20-37.

18. Camp RL, Dolled-Filhart M, Rimm DL. X-tile: a new bio-informatics tool for biomarker assessment and outcome-based cut-point optimization. Clin Cancer Res. 2004;10(21):7252-9.

19. Kong X, Li J, Cai Y, et al. A modified TNM staging system for non-metastatic colorectal cancer based on nomogram analysis of SEER database [J]. BMC Cancer. 2018;18(1):50.

20. Zhang Z, Luo Q, Yin X, et al. Nomograms to predict survival after colorectal cancer resection without preoperative therapy [J]. BMC Cancer. 2016;16(1): 658.

21. Yu C, Zhang Y. Development and validation of a prognostic nomogram for early-onset colon cancer [J]. Biosci Rep. 2019;39(6).

22. Li $D$, Zhong $C$, Tang $X$, et al. Competing nomograms help in the selection of elderly patients with colon cancer for adjuvant chemotherapy [J]. J Cancer Res Clin Oncol. 2018;144(5):909-23.

23. Tan Z, Zhang M, Han Q, et al. A novel blood tool of cancer prognosis in esophageal squamous cell carcinoma: the fibrinogen/albumin ratio [J]. J Cancer. 2017;8(6):1025.

24. Zhou $\mathrm{H}$, Tang $\mathrm{K}$, Xiao $\mathrm{H}$, et al. A panel of eight-miRNA signature as a potential biomarker for predicting survival in bladder cancer [J]. J Exp Clin Cancer Res. 2015;34(1):53.

25. Song K, Shi X, Wang H, et al. Can a nomogram help to predict the overall and cancer-specific survival of patients with chondrosarcoma?[]]. Clin Orthop Relat Res. 2018;476(5):987.

26. Kornprat $\mathrm{P}$, Pollheimer $\mathrm{MJ}$, Lindtner RA, et al. Value of tumor size as a prognostic variable in colorectal cancer: a critical reappraisal [J]. Am J Clin Oncol. 2011;34(1):43-9.

\section{Publisher's Note}

Springer Nature remains neutral with regard to jurisdictional claims in published maps and institutional affiliations.

Ready to submit your research? Choose BMC and benefit from:

- fast, convenient online submission

- thorough peer review by experienced researchers in your field

- rapid publication on acceptance

- support for research data, including large and complex data types

- gold Open Access which fosters wider collaboration and increased citations

- maximum visibility for your research: over $100 \mathrm{M}$ website views per year

At BMC, research is always in progress.

Learn more biomedcentral.com/submissions 